\title{
Stage IIIB Testicular Cancer AJCC v6 and v7
}

National Cancer Institute

\section{Source}

National Cancer Institute. Stage IIIB Testicular Cancer AJCC v6 and v7. NCI Thesaurus. Code C6368.

Stage IIIB includes: (Any pT/TX, N1-3, M0, S2); (Any pT/TX, Any N, M1a, S2). N1:

Metastasis with a lymph node mass $2 \mathrm{~cm}$ or less in greatest dimension; or multiple lymph nodes, none more than $2 \mathrm{~cm}$ in greatest dimension. N2: Metastasis with a lymph node mass more than $2 \mathrm{~cm}$ but not more than $5 \mathrm{~cm}$ in greatest dimension; or multiple lymph nodes, any one mass greater than $2 \mathrm{~cm}$ but not more than $5 \mathrm{~cm}$ in greatest dimension. N3: Metastasis with a lymph node mass more than $5 \mathrm{~cm}$ in greatest dimension. M0: No distant metastasis. M1a: Non-regional nodal or pulmonary metastasis. S2: LDH 1.5-10 x $\mathrm{N}$ ( $\mathrm{N}$ indicates the upper limit of normal for the LDH assay) or hCG $5,000-50,000$ or AFP 1,000-10,000. (AJCC 6th and 7th eds.) 